\title{
Pattern of Eclampsia in a Tertiary Health Facility Situated in a Semi-Rural Town in Northern Nigeria
}

\author{
J. Tukur ${ }^{1}$, B.A. Umar' ${ }^{2}$ A. Rabi'u ${ }^{2}$ \\ ${ }^{1}$ Department of Obstetrics and Gynaecology, Aminu Kano Teaching Hospital/Bayero University, Kano, Nigeria \\ ${ }^{2}$ Department of Paediatrics, Federal Medical Center, Birnin Kudu, Jigawa State, Nigeria \\ Reprint requests to: Dr. J, Tukur, Department of Obstetrics and Gynaecology, Aminu Kano Teaching Hospital, \\ P. M. B. 3452,Kano,Nigeria.E-mail: jtukur@yahoo.com
}

\begin{abstract}
Background/Objective: To determine the pattern of eclampsia and its contribution to maternal mortality at the Federal Medical Centre, Birnin Kudu, Jigawa State in Northern Nigeria.

Method: A 4-year retrospective review of the case records of all women who presented with eclampsia at the center. All the case records were retrieved from the medical record department and analyzed.

Results: There were 207 cases of eclampsia out of 2197 deliveries during the period giving an incidence of $9.42 \% .171(82.6 \%)$ of the patients were unbooked. Majority (58.5\%) of the patients were aged less than 20 years. The highest frequency $(78.3 \%)$ was recorded in the primigravida. Delay before reaching the hospital was established in $116(56 \%)$ of patients. The condition was antepartum in $68(32.9 \%)$, intrapartum in $112(54.1 \%)$ and postpartum in $27(13 \%)$. 107(51.7\%) of the patients were delivered by cesarean section. Twenty two $(10.6 \%)$ of the mothers died. Eclampsia was the commonest cause of maternal mortality and contributed $43.1 \%$ of all maternal deaths. $180(87 \%)$ of the babies were delivered alive while 27(13\%) died.
\end{abstract}

Conclusion: Eclampsia is a major cause of maternal mortality. There is need for health education on the need for patients to avail themselves of antenatal care.

Key words: Eclampsia, maternal mortality

\section{Résumé}

Fond/Objectif: Pour détermine la distribution de l'éclampsie et sa contribution a la mortalité maternelle au centre de santé médical fédéral de Birnin Kudu, état de Jigawa au Nord du Nigeria.

Méthodologie: Ceci est une revue rétrospective pendant quatre ans des cas reportes de toutes les femmes qui se sont présentées avec l'éclampsie a ce centre. Tous ces rapports ont été obtenu au département des rapports médicaux et ont été analyses.

Résultats: Il y a eu 207 cas d'éclampsie permis 2197 naissances. Ceci donne une incidence de $9.42 \%$. $171(82.6 \%)$ de tous ces patients n'ont pas fait de visite prénatale. La majorité des patients $(58.5 \%)$ étaient ages de moins de 20 ans. La fréquence la plus élevée (78.3\%) a été obtenu parmi les primigravid. Le retard avant de se présenter au centre de santé a été étable chez $116(56 \%)$ des patients. La condition était prénatale chez 68 (32.9\%), intra natale chez $112(54.1 \%)$ et postnatale chez 27 (13\%). Chez 107 (51.7\%) patients, l'accouchement s'est fait par caesarienne. 22 (10.6\%) de maman étaient decedees. L'éclampsie était la cause de la mortalité maternelle la plus élevée et a contribue a $43.1 \%$ de tous les décès maternels. 180(87\%) bébés sont nés vivant alois que 27(13\%) étaient mort nes.

Conclusion: L'éclampsie est la cause majeure de la mortalité maternelle. Les patients ont besoin d'être éduques et aussi d'aller aux visites prénatales.

Mots clés: Éclampsie, Mortalité maternelle

\section{Introduction}

Eclampsia is a common cause of maternal mortality worldwide but particularly in the developing countries. It is estimated that every year eclampsia is associated with about 50000 maternal deaths worldwide, most of which occur in developing countries. ${ }^{1}$ A study done in 2004 to assess the status of emergency obstetric care in the different zones of Nigeria by the Society of Gynaecology and Obstetrics of Nigeria (SOGON) revealed eclampsia as a major contributor to maternal mortality in the whole 
country. In Kano State (which is in the same zone as the place where this study was conducted), eclampsia was not only the commonest cause of maternal mortality but also contributed $46.3 \%$ of all the maternal deaths in one study ${ }^{2}$ and $31.3 \%$ in another. ${ }^{3}$ Reports from other centers especially in northern Nigeria also reveal a similar picture of high incidence of eclampsia and contribution to maternal mortality. ${ }^{4,5}$

In the developing countries, there is low utilization of both antenatal and intrapartum care and the patients may present to the hospital only as a last resort. The opportunity to detect women at the preeclamptic phase is therefore usually lost. In addition, the World Health Organisation (WHO) estimates that only $40 \%$ of births in developing countries take place in health facilities. ${ }^{6}$ When delivery care is sought, it is done late, after a lot of delays and this contributes to maternal mortality. Yet, prenatal care and supervision of delivery by trained birth attendants are said to be the best and cost-effective means of reducing maternal and perinatal mortality and morbidity.,

Even for those women who eventually make it to the hospital, they may be attended to in facilities with shortage of staff, equipment and/or drugs. Despite evidence that magnesium sulfate is the most effective anticonvulsant for the prevention and treatment of eclampsia ${ }^{9,10}$ and it has been used in the developing countries and shown to have a favorable maternal and fetal outcome, ${ }^{11,12}$ it has remained unavailable in most centers.

The current study was done to determine the clinical presentation of eclampsia, its management, as well as maternal and fetal complications in patients who presented at Federal Medical Center Birnin Kudu, Jigawa state.

\section{Materials and Methods}

This is a descriptive study of all consecutive patients with eclampsia managed at the Federal Medical Centre, Birnin Kudu between 1st January 2002 and 31st December 2005. Birnin Kudu is a semi urban area located in the savannah region of Northern Nigeria. The hospital is a rural health facility undergoing transformation from a secondary to tertiary facility. It is also a referral center for patients from the neighboring states of Kano and Bauchi. Autopsy was not offered in the facility due to lack of expertise. Eclamptics are generally managed by sedation with intravenous diazepam, treatment of severe hypertension with intravenous hydrallazine and delivering the baby through the safest and fastest means. Magnesium sulfate was not available for use during the period under review.

The case notes of all the patients were retrieved from the Medical Record Department and analyzed. The data obtained included age, parity, ethnic group, booking status (registered for antenatal care and had at least two visits with one of the visits within the last two weeks before delivery), place of delivery, delay before reaching the hospital, type of eclampsia, modality of delivery and the maternal and fetal outcome. The data was analyzed by the use of EPI INFO statistical software version 3.3.2. Comparison of variables was by the student $t$ test with statistically significant value set at p-value $<0.05$.

\section{Results}

There were two hundred and seven (207) patients that presented with eclampsia out of 2197 deliveries during the period giving an incidence of $9.42 \%$. One hundred and seventy one $(82.6 \%)$, of the patients were unbooked. The age and parity distribution are shown in Table 1. Majority (58.5\%) of the patients were aged less than 20 years (range of 15-49). The highest frequency $(78.3 \%)$ was recorded in the primigravida (mean parity was 0.8 standard deviation of 2.1 ). Delay in reaching medical facility (defined as inability to reach the hospital from home within three hours) was established in $116(56 \%)$ of patients. From the records, it was however not possible to determine those who had delays after arrival at the facility before accessing care. One hundred and twenty five $(60.4 \%)$ of the patients premonitory symptom in the form of headache, epigastric pain and/or blurring of vision. The mean number of fits before admission was 5 (range of 1-11; standard deviation 3.6). The clinical type of eclampsia was intrapartum in $112(54.1 \%)$, antepartum in $68(32.9 \%)$ and postpartum in $27(13 \%)$ of the patients. One hundred and seven $(51.7 \%)$ of the patients were delivered by cesarean section while the others had vaginal delivery assisted with vacuum or forceps. For those mothers delivered by cesarean section, there were $95(88.7 \%)$ live babies delivered while for those who had assisted vaginal delivery, there were $85(85 \%)$ live babies delivered. The difference was not statistically significant $(P>.05)$.

Table 1. Distribution of patients by age and parity

\begin{tabular}{|c|c|c|c|c|c|c|c|}
\hline \multirow[t]{2}{*}{ Age group } & \multicolumn{6}{|c|}{ Parity } & \multirow[t]{2}{*}{ Total } \\
\hline & 0 & 1 & 2 & 3 & 4 & $\geq 5$ & \\
\hline 13-19 & 113 & 8 & 0 & 0 & 0 & 0 & 121 \\
\hline $20-29$ & 46 & 9 & 2 & 2 & 7 & 4 & 70 \\
\hline $30-39$ & 2 & 0 & 2 & 1 & 0 & 5 & 10 \\
\hline $40-49$ & 1 & 0 & 1 & 0 & 0 & 4 & 6 \\
\hline Total & 162 & 17 & 5 & 3 & 7 & 13 & 207 \\
\hline
\end{tabular}


Twenty two $(10.6 \%)$ of the patients died. All the deaths were recorded in unbooked patients. This association of mortality with failure to book for antenatal care was statistically significant $(P<.05)$. Among the patients that died, delay was demonstrated among $18(81.8 \%)$ of them and this was statistically significant $(P<.05)$. During the period under review fifty one maternal deaths were recorded (Table 2). Eclampsia was the commonest cause of maternal mortality during the period, contributing $22(43.1 \%)$ of the deaths. One hundred and eighty $(87 \%)$ of the babies were delivered alive while $27(13 \%)$ died within one week of delivery. There was only one case of twin pregnancy while the rest were singleton.

Table 2. Causes of Maternal Mortality at Federal Medical Centre, Birnin Kudu, Nigeria (2002-2005)

\begin{tabular}{lll}
\hline Diagnosis & No. & \% \\
\hline Eclampsia & 22 & 43.1 \\
Anaemia & 6 & 11.8 \\
Obstructed labor & 5 & 9.8 \\
Antepartum hemorrhage & 4 & 7.8 \\
Postpartum hemorrhage & 4 & 7.8 \\
Puerperal sepsis & 4 & 7.8 \\
Ruptured uterus & 3 & 5.9 \\
Hepatitis & 1 & 2.0 \\
Meningitis & 1 & 2.0 \\
Chronic liver disease & 1 & 2.0 \\
\hline Total & 51 & 100 \\
\hline
\end{tabular}

\section{Discussion}

The incidence of eclampsia in this study was $9.42 \%$. This was higher than that reported from Kaduna $(0.42 \%){ }^{4}$ Sokoto $(4.29 \%),{ }^{5}$ Nnewi $(0.75 \%),{ }^{13}$ all in Nigeria and also Kathmandu, Nepal $(0.29 \%) .{ }^{14}$ The higher prevalence in this study is probably as a result of two major reasons. First, was the rather low use of antenatal services. Majority of the patients $(82.6 \%)$ never utilized any form of antenatal care throughout the pregnancy. If they had benefited from antenatal care, pre-eclampsia could have been detected and some form of treatment offered before the disease progressed to eclampsia. This may include stopping the pregnancy by induction or cesarean section. Second, our patients had tendency to delay reaching the health facility as this was demonstrated in $56 \%$ of them.

Eclampsia was noted to be commoner among the young primigravida patients. This finding is consistent with that of other studies. ${ }^{4,5,13}$ The importance of this finding is that this group of patients deserve extra surveillance during antenatal care in terms of monitoring their blood pressure and screening their urine for proteinuria to detect preeclampsia.

Delay in reaching the health facility was recorded in $56 \%$ of the patients. It is therefore not surprising that the mean number of fits in the patients was 5. It is not clear from the records if there were other patients who may have had delays at the facility before accessing care. The delay in accessing medical care and the high number of fits prior to medical intervention could have contributed to the rather high mortality of $10.6 \%$ of the patients. Eclampsia was the commonest cause of maternal mortality for the period. The case fatality rate of $10.6 \%$ due to eclampsia is comparable to the $9.3 \%$ reported from Nnewi ${ }^{13}$ and $11.6 \%$ reported from Gombe. ${ }^{15}$ The finding that eclampsia was responsible for $43.1 \%$ of all the maternal deaths recorded in the Centre is also similar to the $46.1 \%$ in Kano State as recorded in the SOGON study. $^{2}$ Jigawa and Kano states share common borders and their people's culture and beliefs. The perinatal mortality rate was $130 / 1000$ deliveries. This was lower than the $368 / 1000$ deliveries reported from Gombe $^{15}$ and 409/1000 reported from Kaduna. ${ }^{16}$

This study confirms that eclampsia is still a major cause of maternal and perinatal mortality in our environment. A major association appears to be lack of utilization of antenatal care and delay at accessing skilled care during delivery. To address this problem, there is need for community health education to increase the awareness of pregnant women to avail themselves of antenatal care and safe delivery in the nearest health post. Reduction on poverty and improvement of the socio economic condition of the citizens will make them afford health care. The National Health Insurance Scheme has been introduced by the Nigerian government. It is a form of contributory social security and offers health care that is acceptable and affordable to the community. It needs to be extended to reach the rural areas so that the poor ones can access care. There is need to improve roads, transportation as well as communications.

With the recent establishment of intensive care facilities for adults and babies in the Center, it is will be interesting to evaluate such intervention on the morbidity and mortality of mothers and their babies in the near future. Furthermore, the construction of a new antenatal clinic and an operation theater for the exclusive use of operative deliveries is at the final stage of completion. It is hoped that such interventions will have positive impact on maternal and child care. It is noted that the Nigerian government has focused its attention to these issues in the Millennium Development Goals (MDG) it set to achieve by the target date of $2015 .^{17}$ At the time of writing this report efforts are being made to procure and make magnesium sulfate available for use in the treatment of eclampsia in consideration of its superiority over diazepam.

\section{References}

1. Duley L. Maternal mortality associated with hypertensive disorders of pregnancy in Africa, Asia, Latin America and the Caribbean. Br J Obstet Gynaecol. 1992;99:547-553. 
2. Status of emergency obstetric service in six states of Nigeria- A needs assessment report. Society of Gynaecology and Obstetrics of Nigeria. 2004.

3. Adamu YM, Salihu HM, Sathiakumar N, Alexander R. Maternal mortality in Northern Nigeria: a population based study. Eur J Obstet Gynecol Reprod Biol. 2003;109:153-159.

4. Onwuhafua PI, Onwuhafua A, Adze J, Mairami Z. Eclampsia in Kaduna State of Nigeria: a proposal for a better outcome. Niger J Med. 2001;10:81-84.

5. Ekele BA, Bello SO, Adamu AN. Clusters of eclampsia in a Nigerian teaching hospital. Int $\mathrm{J}$ Gynaecol Obstet. 2007;96:62-66.

6. WHO. Coverage of maternity care. A list of available information. Geneva, Switzerland. Maternal and newborn health/Safe Motherhood. 1997.

7. Harrison KA. Maternal mortality - a sharper focus on a major issue of our time. Trop J Obstet Gynaecol. 1988;1:9-13.

8. Mc Donald TI, Coburn A. Predictors of prenatal care utilisation. Soc Sci Med. 1988;27:167-172.

9. The Eclampsia Trial Collaborative Group. Which anticonvulsant for women with eclampsia? Evidence from the Collaborative Eclampsia Trial. Lancet. 1995;345:1455-1463.
10. Atallah AN. Anticonvulsant therapy for eclampsia. RHL commentary. The WHO Reproductive Health Library No 8. Update Soft ware Ltd, Oxford, 2005.

11. Ekele BA, Badung SL. Is serum magnesium estimate necessary in patients on magnesium sulphate? Afr J Reprod Health. 2005;9:128-132.

12. Adewole IF, Oladokun A, Okewole AI, et al. Magnesium sulphate for treatment of eclampsia: the Nigerian experience. Afr J Med Sci. 2000;29:239-241.

13. Ikechebelu JI, Okoli CC. Review of eclampsia at the Nnamdi Azikiwe University Teaching Hospital, Nnewi. J Obstet Gynaecol. 2002;22:287-290.

14. Choudhary P. Eclampsia: a hospital based retrospective study. Kathmandu Univ Med J. 2003;1:237-241.

15. El- Nafaty AU. Melah GS, Massa AA, Audu BM, Nelda M. The analysis of eclamptic morbidity and mortality in the Specialist Hospital Gombe, Nigeria. J Obstet Gynaecol. 2004;24:142-147.

16. Onwuhafua PI, Oguntayo A. Perinatal mortality associated with eclampsia in Kaduna, Northern Nigeria. Niger J Med. 2006;15:397-400.

17. 17. Nigeria Health. Nutrition and Population Country Status Report. World Bank Report 2005; Vol II. Nov: 21-25. 